\title{
Atmospheric Radiation Measurement Program Climate Research Facility Operations Quarterly Report
}

October 1- December 31, 2010 


\section{DISCLAIMER}

This report was prepared as an account of work sponsored by the U.S. Government. Neither the United States nor any agency thereof, nor any of their employees, makes any warranty, express or implied, or assumes any legal liability or responsibility for the accuracy, completeness, or usefulness of any information, apparatus, product, or process disclosed, or represents that its use would not infringe privately owned rights. Reference herein to any specific commercial product, process, or service by trade name, trademark, manufacturer, or otherwise, does not necessarily constitute or imply its endorsement, recommendation, or favoring by the U.S. Government or any agency thereof. The views and opinions of authors expressed herein do not necessarily state or reflect those of the U.S. Government or any agency thereof. 


\section{Atmospheric Radiation Measurement Program Climate Research Facility Operations Quarterly Report}

October 1-December 31, 2010

Work supported by the U.S. Department of Energy,

Office of Science, Office of Biological and Environmental Research 


\section{Contents}

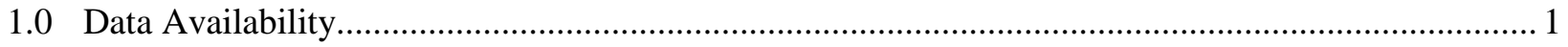

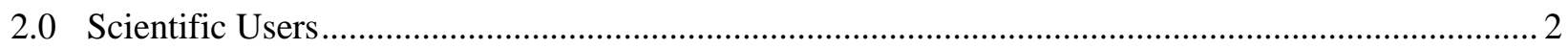

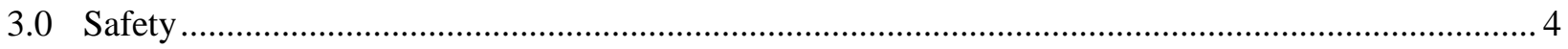

\section{Tables}

Table 1. Operational Statistics for the Fixed ARM Sites and Mobile Facilities for the

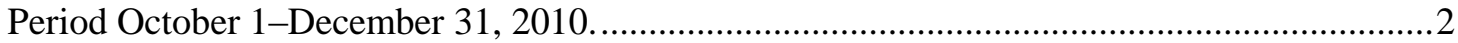

Table 2. Summary of ARM Scientific Users for the Period October 1-December 31, 2010. 4

Table 3. Consecutive Days of Injury-Free Operation, * October 1-December 31, 2010.....4 


\section{Atmospheric Radiation Measurement Program Climate Research Facility Operations Quarterly Report October 1-December 31, 2010}

\subsection{Data Availability}

Description. Individual raw datastreams from instrumentation at the Atmospheric Radiation Measurement (ARM) Climate Research Facility fixed and mobile sites are collected and sent to the Data Management Facility (DMF) at Pacific Northwest National Laboratory (PNNL) for processing in nearreal time. Raw and processed data are then sent approximately daily to the ARM Archive, where they are made available to users. For each instrument, we calculate the ratio of the actual number of processed data records received daily at the Archive to the expected number of data records. The results are tabulated by (1) individual datastream, site, and month for the current year and (2) site and fiscal year (FY) dating back to 1998 .

The U.S. Department of Energy (DOE) requires national user facilities to report time-based operating data. The requirements concern the actual hours of operation (ACTUAL); the estimated maximum operation or uptime goal (OPSMAX), which accounts for planned downtime; and the VARIANCE [1 - (ACTUAL/OPSMAX)], which accounts for unplanned downtime. The OPSMAX time for the first quarter of FY2010 for the Southern Great Plains (SGP) site is 2097.60 hours $(0.95 \times 2208$ hours this quarter). The OPSMAX for the North Slope Alaska (NSA) locale is 1987.20 hours $(0.90 \times 2208)$ and for the Tropical Western Pacific (TWP) locale is 1876.80 hours $(0.85 \times 2208)$. The first ARM Mobile Facility (AMF1) deployment in Graciosa Island, the Azores, Portugal, continued through this quarter, so the OPSMAX time this quarter is 2097.60 hours (0.95 x 2208). The second ARM Mobile Facility (AMF2) began deployment this quarter to Steamboat Springs, Colorado. The experiment officially began November 15, but most of the instruments were up and running by November 1 . Therefore, the OPSMAX time for the AMF2 was 1390.80 hours $(.95 \times 1464$ hours) for November and December (61 days). The differences in OPSMAX performance reflect the complexity of local logistics and the frequency of extreme weather events. It is impractical to measure OPSMAX for each instrument or datastream. Data availability reported here refers to the average of the individual, continuous datastreams that have been received by the Archive. Data not at the Archive are caused by downtime (scheduled or unplanned) of the individual instruments. Therefore, data availability is directly related to individual instrument uptime. Thus, the average percentage of data in the Archive represents the average percentage of the time ( 24 hours per day, 92 days for this quarter) the instruments were operating this quarter.

Summary. Table 1 shows the accumulated maximum operation time (planned uptime), actual hours of operation, and variance (unplanned downtime) for the period October 1-December 31, 2010, for the fixed sites. Because the AMFs operate episodically, the AMF statistics are reported separately and not included in the aggregate average with the fixed sites. This first quarter comprises a total of 2,208 possible hours for the fixed sites and the AMF1 and 1,464 possible hours for the AMF2. The average of the fixed sites exceeded our goal this quarter. The AMF1 has essentially completed its mission and is shutting down to pack up for its next deployment to India. Although all the raw data from the operational instruments are in the Archive for the AMF2, only the processed data are tabulated. Approximately half of the AMF2 instruments have data that was fully processed, resulting in the $46 \%$ of all possible data made available to 
users through the Archive for this first quarter. Typically, raw data is not made available to users unless specifically requested.

Table 1. Operational Statistics for the Fixed ARM Sites and Mobile Facilities for the Period October 1-December 31, 2010.

\begin{tabular}{|c|c|c|c|c|c|}
\hline \multirow{2}{*}{ Site } & \multicolumn{2}{c|}{ Hours of Operation } & \multicolumn{2}{c|}{ Data Availability } \\
\cline { 2 - 6 } & OPSMAX & Actual & Variance & Goal & Actual \\
\hline NSA & 1987.20 & 2097.60 & -0.0556 & 0.90 & 0.95 \\
\hline SGP & 2097.60 & 2053.44 & +0.0211 & 0.95 & 0.93 \\
\hline TWP & 1876.80 & 2185.92 & -0.1647 & 0.85 & 0.99 \\
\hline Site Average & 1987.20 & 2112.32 & -0.0630 & 0.90 & 0.96 \\
\hline AMF1 Azores, PT & 2097.60 & 2053.44 & +0.0211 & 0.95 & 0.93 \\
\hline AMF2 Colorado, USA & 1390.80 & 637.44 & +0.5158 & 0.95 & 0.46 \\
\hline
\end{tabular}

\subsection{Scientific Users}

Description. The Site Access Request System is a web-based database used to track visitors to the fixed and mobile sites, all of which have facilities that can be visited. The NSA locale has the Barrow and Atqasuk sites. The SGP site has historically had a Central Facility, 23 extended facilities, 4 boundary facilities, and 3 intermediate facilities. Beginning in October 2009, the SGP began a transition to a smaller footprint $(150 \mathrm{~km} \times 150 \mathrm{~km})$ by rearranging the original and new instrumentation made available through the American Recovery and Reinvestment Act (ARRA). The Central Facility and 4 extended facilities will remain, but there will be up to 12 new surface characterization facilities, 4 radar facilities, and 3 profiler facilities sited in the smaller domain. This new configuration will provide observations at scales more appropriate to current and future climate models. The transition to the smaller footprint was ongoing through this quarter. The TWP locale has the Manus, Nauru, and Darwin sites. These sites will also have expanded measurement capabilities with the addition of new instrumentation made available through ARRA funds. It is anticipated that the new instrumentation at all the fixed sites will be in place by the end of fiscal 2011. This quarter the AMF1 essentially completed its 20-month deployment in Graciosa Island, Azores, Portugal, which began on May 1, 2009. It is anticipated that the AMF1 will be deployed to India during the next quarter and that the new ARRA observational capabilities will be added to the AMF1 during setup in India. The second ARM Mobile Facility (AMF2) was deployed this quarter to Steamboat Springs, Colorado, in support of the Storm Peak Lab Cloud Property Validation Experiment (StormVEx). The first field deployment of the second ARM mobile facility will be used to validate ARM developed algorithms that convert the remote sensing measurements to cloud properties for liquid and mixed-phase clouds. It is anticipated that the new ARRA observational capabilities will be added to the AMF2 in Colorado as they become available. The first operational day for the AMF2 was November 15, 2010.

Users can participate in field experiments at the sites and mobile facilities, or they can participate remotely. Therefore, there are a variety of mechanisms provided to users to access site information. Users who have immediate (real-time) needs for data access can request a research account on the local site data 
systems. This access is particularly useful to users for quick decisions in executing time-dependent activities associated with field campaigns at the fixed site and mobile facility locations. The eight computers for the research accounts are located at the Barrow and Atqasuk sites; the SGP Central Facility; the TWP Manus, Nauru, and Darwin sites; the AMFs; and the DMF at PNNL. However, users are warned that data provided at the time of collection are not fully screened for quality and therefore not considered to be official ARM data. Hence, these accounts are considered to be part of the facility activities associated with field campaign activities, and users are tracked. Fully screened and approved ARM data are officially requested through the ARM Archive.

In addition, users who visit sites can connect their computer or instrument to an ARM site data system network, which requires an on-site device account. Remote (off-site) users can also have remote access to any ARM instrument or computer system at any ARM site, which requires an off-site device account. These accounts are also managed and tracked.

Official ARM data collected through the routine operations and scientific field experiments at the fixed sites and mobile facility that have passed through the formal data quality review process are stored at and distributed through the Archive. The Archive receives fully quality assured data within $24-48$ hours of the collection and processing of data that takes place at the DMF. These data are available to the public free of charge.

The Archive also serves as a data repository for atmospheric data at the long-term Arctic atmospheric observatory in Eureka, Canada $\left(80^{\circ} 05^{\prime} \mathrm{N}, 86^{\circ} 43^{\prime} \mathrm{W}\right)$, as part of the multiagency Study of Environmental Arctic Change (SEARCH) Program. NOAA began providing instruments for the site in 2005 . The intent of the site is to monitor the important components of the Arctic atmosphere, including clouds, aerosols, atmospheric radiation, and local-scale atmospheric dynamics. Because of the similarity of ARM NSA datastreams and the important synergy that can be formed between a network of Arctic atmospheric observations, the SEARCH radar data are archived in the ARM Archive. Instruments will be added to the site over time. The designation for the archived Eureka data is YEU and is now included in the ARM user metrics.

DOE requires national user facilities to report facility use by total visitor days - broken down by institution type, gender, race, citizenship, visitor role, visit purpose, and facility - for actual visitors and for active user research computer and Archive accounts. This information is maintained but not presented in this report. Visitor role and visit purpose information are used to identify scientific users. Based on the users' self-provided information about their role and visit purpose, the following types of users are categorized as scientific users: Principal and Co-Principal Investigators, Postdoctorates, Graduate Students, Undergraduate Students, Infrastructure Instrument Mentors, and Infrastructure Chief and Site Scientists. Although other categories can be identified, they are considered nonscientific. They are reported here for completeness.

This quarterly report provides the cumulative numbers of scientific user accounts by site for the period October 1-December 31, 2010. Only scientific users are officially counted, and they are determined by the sum of unique scientific users for each of the ARM facility components. As before, all user accounts are established for a period of up to one year and must be renewed. To report users, we count the number of active users for the previous 12 months during the last month of the quarterly reporting period. 
Summary. Table 2 shows the summary of cumulative scientific and nonscientific users for the period October 1-December 31, 2010. While the number of ARM unique users was 1,321 in total, 963 were characterized as unique scientific users. In addition to the AMF1 deployment in the Azores, ARM supports field campaigns that are not located with any of the fixed sites. The users statistics for off-site campaigns were included with the AMF1 tally. For a complete listing of field campaigns, please refer to the ARM web link: http://www.arm.gov/campaigns/table. The large increase in users this period is mostly attributed to the AMF2 StormVEx field campaign.

Table 2. Summary of ARM Scientific Users for the Period October 1-December 31, 2010.

\subsection{Safety}

\begin{tabular}{|r|c|c|}
\hline $\begin{array}{c}\text { ARM Facility } \\
\text { Component }\end{array}$ & $\begin{array}{c}\text { Unique } \\
\text { Scientific Users }\end{array}$ & $\begin{array}{c}\text { Unique } \\
\text { NonScientific } \\
\text { Users }\end{array}$ \\
\hline $\begin{array}{r}\text { AMF1 (Azores) and } \\
\text { Off-Site Campaigns }\end{array}$ & 17 & 13 \\
\hline AMF2 (Colorado) & 38 & 38 \\
\hline NSA & 32 & 38 \\
\hline SGP & 65 & 122 \\
\hline TWP & 26 & 22 \\
\hline DMF & 38 & 59 \\
\hline Archive & 747 & 66 \\
\hline Total & 963 & 358 \\
\hline
\end{tabular}

For reporting purposes, the three ARM sites and the two AMFs operate 24 hours per day, 7 days per week, and 52 weeks per year. Time is reported in days instead of hours. If any lost work time is incurred by any employee, it is counted as a workday loss. Table 3 reports the consecutive days since the last recordable or reportable injury or incident causing damage to property, equipment, or vehicles for the period October 1December 31, 2010. There were no recordable lost workday cases or reportable injury or incidents causing damage to property, equipment, or vehicles reported for the first quarter of FY2011.

Table 3. Consecutive Days of Injury-Free Operation,* October 1-December 31, 2010.

\begin{tabular}{|r|c|c|c|c|c|}
\hline ES\&H Category & NSA & SGP & TWP & AMF1 & AMF2 \\
\hline Days Worked without a Lost-Time Incident & 92 & 92 & 92 & 92 & 92 \\
\hline Days Worked without a Recordable Accident & 92 & 92 & 92 & 92 & 92 \\
\hline Days Worked without a Property Damage Incident & 92 & 92 & 92 & 92 & 92 \\
\hline Days Worked without a Reportable Loss to Vehicles & 92 & 92 & 92 & 92 & 92 \\
\hline
\end{tabular}




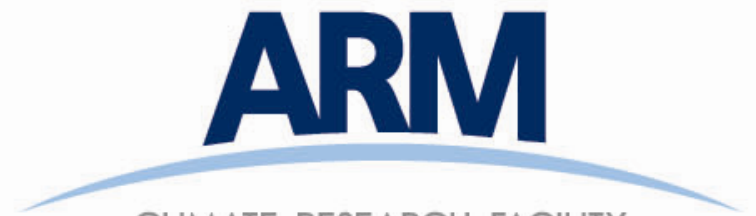

CLIMATE RESEARCH FACILITY

www.arm.gov

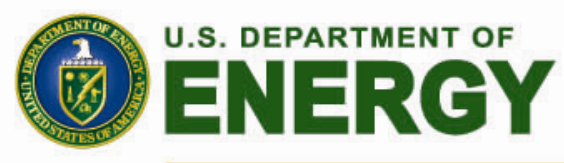

Office of Science 